$\begin{array}{llllllllllllllllllll}A & R & T & I & C & U & L & O & D & E\end{array}$ $\begin{array}{lllllllll}R & E & F & L & E & X & I & O & N\end{array}$

\section{Vidas paralelas (México y Perú). ENCINAS Y VASCONCELOS, EDUCAR PARA LA NACIÓN}

PARALLEL LIVES (MEXICO AND PERU). ENCINAS AND VASCONCELOS, EDUCATE FOR THE NATION

Por: Iván Isaac Caldas Figueroa*

* Educador por la Universidad Nacional Federico Villareal, Antropólogo y Magister en Historia por la Universidad

Nacional Mayor de San

Nacional Mayor de Sa Marcos, catedrático de la Universidad Nacional Mayor de San Marcos, Perú. Miembro de la Sociedad Fundadores de la Independencia. Email: ivan_caldas_f@ yahoo.es

Recibido: 1 de marzo de 2017 - Aprobado: 31 de mayo de 2017

\section{RESUMEN}

Nuestros países latinoamericanos son muy parecidos en su camino histórico, en la política, el arte, los movimientos populares, las crisis y traiciones. En este trabajo quiero mostrar mi análisis y reflexión sobre el proceso socio-político de las campañas educacionales del mundo azteca y del mundo andino. Para ello, los pensadores José Vasconcelos y José Antonio Encinas de México y del Perú, respectivamente, son piezas claras y definitivas en este proceso que se delimita temporalmente en las dos primeras décadas del siglo XX. Encuentro que, si bien se parecen en su programa, en su pedagogía moderna, en la defensa de los derechos del indígena, difieren en el contexto político que los rodeó; Vasconcelos fue reforzado por una revolución campesina, Encinas terminó boicoteado por hacendados y la Iglesia Católica.

Palabras clave: indigenismo, nación, México, Perú, proyecto educativo.

\section{SUMMARY}

Our Latin American countries are very similar in their historical path, in politics, art, popular movements, crises and betrayals. In this paper, an analysis and reflection on the socio-political process of the educational campaigns of the Aztec world and the Andean world it is showed. For this, the thinkers José Vasconcelos and José Antonio Encinas from Mexico and Peru, respectively, are clear and definitive pieces in this process that is temporarily delimited in the first two decades of the twentieth century. Although they are similar in their program, in their modern pedagogy, in the defense of the rights of the indigenous, they differ in the political context that surrounded them; Vasconcelos was reinforced by a peasant revolution, Encinas ended boycotted by landlords and the Catholic Church.

Keywords: indigenism, nation, Mexico, Peru, educational project. 


\section{Introducción}

rabajando mi tesis de maestría sobre el maestro peruano José Antonio Encinas, encontré que sus ideas y actos públicos se _ enmarcaban dentro de los postulados de la Escuela Nueva, aquel proyecto educativo que llegó con potente impacto en Latinoamérica a fines del siglo XIX e inicios del XX. Así, noté que muchos otros intelectuales de nuestra región emprendieron caminos de vida con parecido paradigma. Me refiero a la modernidad, el encanto en la vida liberal, un hechizo profundo por los derechos de la población indígena, una confianza en la educación llevada en la sangre.

Noté que en México, la revolución de muchos campesinos y artistas de 1910, tuvo como líder educacional a José Vasconcelos. Me pregunté, entonces, qué tendrían de semejante y qué de diferente estos dos grandes titanes de la política educacional, Encinas y Vasconcelos; quería saber cuáles habrían sido las motivaciones, miedos y angustias durante sus luchas en la universidad, en las escuelas y en la vida pública. Por si fuera poco, tengo muy presente que los cambios en el agro, los debates por las leyes laborales de la revolución mexicana, así como sus caudillos, Francisco Madero, Pancho Villa y Emiliano Zapata, fue bastante admirada por muchos peruanos involucrados en la política, en la lucha obrera, en la vida universitaria e intelectual, por lo tanto había inquietudes que ameritaban una investigación.

Como llevado por una nube de Atenea, me puse a contrastar los textos y los intereses de estos dos maestros, a estudiar dentro de un esquema de historia intelectual, las tensiones y desencuentros de sus vidas, a revisar el escenario socio-político que significó el remolino social que vivieron ambos para plasmar sus proyectos educativos. Recordando al clásico Plutarco, realizo este pequeño trabajo sobre dos vidas que representan dos pueblos, dos caminos, dos luces en la historia de los maestros e intelectuales de nuestra América.

\section{Hombres de su tiempo}

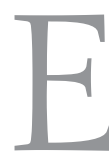

stos dos intelectuales y actores políticos, muy semejantes en su orientación académica y en los avatares de sus vidas, nos ocupan en este trabajo comparativo. Vivieron prácticamente la misma época, ${ }^{1}$ José Antonio Encinas (JAE) nació en 1886 y José Vasconcelos (JV) en 1882; el primero en Puno (Perú) y el segundo en Oaxaca (México). Ambos

1 Los años finales del siglo XIX y principios del XX señalan el advenimiento de la potencia EEUU. Sus empresas avanzan con ímpetu de imperialismo en América Latina, inversiones petroleras, mineras, comercio, control de rutas marítimas y fuerte presión políticofinanciera. 
se dedicaron al derecho y a la educación, escribiendo apasionadamente y, con elegancia, sobre la construcción de la nación, sobre el problema de la población indígena y sus anhelos en la cultura y el manejo del Estado. Los dos tenían una formación y lecturas de carácter multidisciplinario, un desarrollo académico forjado en universidades decanas y de mucha tradición de sus respectivos países (la Universidad Nacional Mayor de San Marcos de Lima y la Universidad Nacional de México), así como en centros académicos del mundo. Residieron en muchos países, europeos y latinoamericanos, por los continuos destierros a los que fueron sometidos, víctimas del autoritarismo y el militarismo, fenómenos sociales muy típicos de nuestra América Latina.

Nuestros protagonistas tuvieron gran interés en participar en política, intelectuales que compaginaban el estudio de gabinete y la reflexión académica con el debate político y la administración burocrática. JAE vivió y luchó contra el civilismo, ese partido oligárquico conformado por unas cuantas familias de hacendados agro-exportadores; atacaba el abuso social que se implementó contra los indígenas, a cargo de los llamados gamonales, denominación que se le dio a los dueños de tierras en la sierra sur, donde nació y creció. Encinas denunció al clero católico por los escándalos que hacían y el abandono de la educación pública y la explotación del indígena y la ausencia de un nacionalismo que integre a la población.

Vasconcelos vivió el proceso revolucionario mexicano de 1910, una lucha intensa por la tierra que se convirtió en modelo para muchos líderes revolucionarios e intelectuales del Caribe y Sudamérica. Miles de campesinos y pequeños propietarios participaron junto a la clase media contra el Porfirismo, esa etapa dictatorial a cargo de Porfirio Díaz, que duró, increíblemente, más de tres décadas. JV se unió al movimiento antireeleccionista y apoyó a Francisco Madero, más adelante se convirtió en un pensador del mestizaje, rector universitario, ensayista y secretario de Instrucción Pública y Bellas Artes.

Encinas dirigió en 1907 una pequeña escuela en su Puno natal, el Centro Escolar $\mathrm{N}^{\circ}$ 881, convirtiendo esta escuela municipal en un laboratorio pedagógico, poniendo en práctica los postulados de la corriente pedagógica de la Escuela Nueva (Tord 1978) durante cuatro años, a pesar de los obstáculos del clero conservador y de la indiferencia de las autoridades gubernamentales. El proyecto educativo de JAE, es decir, su programa 
escolar se adhería a la modernidad de los estudios liberales, la formación práctica, el uso de la racionalidad y el rechazo a la intromisión clerical en la vida socio-política. Exigía, con mucha decisión, que las tierras pasasen a poder de los indígenas.

En 1919 JAE alcanza una curul en el parlamento, esperanzado en el relativo proyecto modernizador del gobierno pro-norteamericano de Augusto Leguía (1919-1930), aunque años después, decepcionado, pasó a la oposición. En cierta oportunidad, en la Cámara de Diputados al pedir la nominación de una comisión revisora de títulos de propiedad de tierras, según contó Emilio Romero, el otro puneño educador y autor del libro La historia económica, aquella "actitud revolucionaria conmovió al país" (Tord 1978: 15).

En la tierra azteca Vasconcelos, luego de ser maderista, fue desterrado por criticar el proceder del gobernante Venustiano Carranza. También había prestado apoyo a otro caudillo, Victoriano Huerta, dirigiendo la Escuela Nacional Preparatoria. Durante la presidencia de Eulalio Gonzales ocupó la secretaria de la Instrucción Pública y más tarde fue nombrado Rector de la Universidad Nacional de México en 1920; en todas estas instancias, mostró su interés en construir una nación, un cuerpo sólido, con bases en el nuevo mexicano, el mestizo.

Encinas, igualmente perseguido y encarcelado, otras veces expulsado del país, aprovecha el exilio para estudiar en Guatemala, Inglaterra y Francia. En 1932, con apoyo de profesores y estudiantes provincianos, ocupa el rectorado de la Universidad Nacional Mayor de San Marcos y realiza un proceso de reformas; Rodrigo Montoya dijo una vez:

"en Puno, 1930, sostenían que la educación debía hacerse en quechua y aimara primero...el caso del sur andino y en particular el de Puno es el mejor laboratorio de experiencias educativas. No es gratuito que de allí salga Encinas, que lleva a San Marcos, a fines de los años 20 y comienzos de los 30, esta idea de una nueva educación adaptada a las condiciones indígenas" (Montoya, 1987: 81).

Efectivamente, el ímpetu que traía Encinas, esto es, un rico menú de escuela nueva, educación para el trabajo y una formación laica, bebió de las fuentes de un indigenismo pujante de los Andes sureños entremezclado 
2 Para mayor informa-

ción de este concepto

puede revisarse a Hugo

Neira, 2000. con modernas ideas de libre pensamiento educacional de los adventistas que llegaron de Argentina y Bolivia a Puno, donde fundaron escuelas rurales y polemizaron con el credo católico. Sin embargo, la dictadura del militarista Sánchez Cerro cerró la Universidad en 1932 dejándola, por tres largos años, en el oscurantismo.

Por su parte, Vasconcelos, en Mesoamérica, fundó El Ateneo de la Juventud para impulsar la cultura nacional, escribió importantes libros de corte sociológico y poético como Ulises criollo, La raza cósmica, La tormenta, El proconsulado, La flama. La difusión del muralismo indigenista es uno de los logros más aplaudidos de Vasconcelos, aquella férrea lucha por reivindicar a la población nativa, a través de pintores destacados como Orozco, Siqueiros y Rivera. En 1940, al regresar de uno de sus tantos destierros, asume la dirección de la Biblioteca Nacional. Recibió homenajes y loas, ha sido considerado un pensador original, dedicado a la estética, la poesía, criticado por otros por su cercanía al fascismo. Sin embargo, su labor por las aulas y el arte hace expresar a muchos, sublimes comentarios como "fue la primera tentativa del siglo mexicano para abolir el militarismo por la vía del saber" (Arreola, 2009: 2).

El puneño Encinas fundó en Lima el Colegio Dalton para implementar sus ideas renovadoras en la educación, fundó el Instituto Indigenista y se dedicó a publicar la colección Biblioteca Peruana, con temas alusivos a la cultura andina y a los problemas de la realidad nacional.

\section{El contexto latinoamericano}

- os dos intelectuales que presentamos en este estudio comparativo, encajan perfectamente en la categoría de intelligentsia ${ }^{2}$, concepto \lrcorner por el cual se entiende a los intelectuales que están comprometidos con su sociedad y con su época, que no solo se dedican a la cátedra o a escribir textos de alcance nacional e internacional, sino que también son actores políticos y buscan una trasformación de su sociedad. Ambos estaban preocupados en la conformación de la nacionalidad, entendiendo este complejo concepto como el cuerpo socio-político-cultural en el cual se englobe a todos los integrantes de un territorio y se encaminen a un proyecto conjunto. En este programa ellos tienen una perspectiva integradora, una visión donde el indio sea incorporado en la sociedad, esto es, brindar al indio las herramientas educativas para convertirlo en un ciudadano, en un sujeto de derecho; el conocimiento, colocado como eje y 
cuestión básica para ingresar a la cultura universal. El Estado también es otro punto de importancia para estos autores, se nota la gran inquietud en ellos por acceder a las altas esferas gobiernistas. Vasconcelos colaboró con varios presidentes que surgieron de la revolución que hizo caer a Porfirio Díaz. Encinas, por su parte, terminó desplazado y borrado de la campaña gobiernista por la maquinaria de los poderosos del manejo de la cosa pública.

Evidentemente hay una gran diferencia; mientras JV era partícipe de un proceso de cambios en la estructura agraria azteca, ya que, progresivamente, desde 1917 los gobernantes llevaron a cabo reparto de tierras, otorgaban leyes avanzadas con derechos laborales y la efervescencia nacionalista cubría a gran parte de los mexicanos, JAE, en cambio, era un francotirador, un solitario que abogaba por reformas en el mundo andino, que los gobiernos aristocráticos y obispos dogmáticos reprimían. Contra lo sucedido en el área mexicano, el Perú respiraba un aire pesado de los gobiernos conservadores: el civilismo marginaba a la población indígena, se les hacía padecer el enganche (un adelanto de la paga que nunca se completaba), el yanaconaje (un trabajo agrícola en las tierras de un hacendado regional, de increíbles remembranzas del medioevo) dentro de un escenario oscurantista y de analfabetismo ${ }^{3}$. Eran pocos intelectuales los que reclamaban una reforma agraria, itierra para el campesino y derechos! era su grito de batalla, "indigenistas fuimos llamados despectivamente, como si fuéramos miembros inferiores de un grupo partidario de los indios pobres, tristes y oscuros" vuelve a recordarnos Emilio Romero (Tord, 1978: 15). Ser indigenista era mal visto por las autoridades y por algunas personalidades progresistas, pues consideraban que el indigenista era un intelectual urbano, ideologizado, partidario de una moda curiosa.

Vasconcelos se movía en un medio político algo favorable para su proyecto, Encinas iba contra la corriente, si bien la dictadura, denominada el Oncenio de Leguía, fue modernizador en lo urbano, no rompió con el latifundismo y se dedicó a la demagogia, aunque esto ya no era música nueva sino ruido monótono en el escenario andino.

\section{El proyecto educativo}

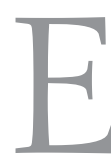

stos dos intelectuales y activistas tenían un pensamiento que recibió la savia influyente del paradigma de la modernidad, fusión de positivismo e ilustración, humanismo envuelto en el ideal del
3 Puede consultarse a Flores Galindo \& Burga (1982) quienes evalúan el procedimiento del comercio lanar y agrícola en el sur andino, así como explican la alianza del poder político de la oligarquía de hacendados y gamonales con una ideología católica conservadora. 
progreso; he ahí el eje de su programa educativo, el cual debía construirse en un nuevo currículo, en un plan de acción estatal. Poseían un claro entusiasmo en el conocimiento, dos hombres que configuran plenamente la tarea educativa como una fusión de técnica y arte que logre convertir a una persona subordinada en un ser autónomo. Fueron dos intelectuales que soñaban con la utopía de convertir al indio en un ciudadano, con plenos poderes, derechos y adquiriera el conocimiento para mostrarse al mundo tal cual, como personas y libertad de opinión; de conducirse sin heteronomía en la cultura moderna.

Encinas decía que ser profesor de aula es la labor más importante en una sociedad, que los indios no necesitan abogados, sino pedagogos (Encinas, 1932). Sentía que los indios del Perú son los verdaderos dueños de la tierra "históricamente, es el dueño del territorio del Perú, él lo ha trabajado y lo ha defendido...el ideal educativo nacionalista debe enfocar la totalidad de su acción en el indio. Desgraciadamente hasta hoy nada se ha hecho por él" (Encinas, 1932).

Vasconcelos habla desde los mestizos, siente que el nuevo hombre que busca es diferente a españoles, a gringos, a Franceses, tiene una idea criolla de nacionalidad, de la modernidad y legalidad (Blanco, 1982). Elaboró un lema que servirá de símbolo para la Universidad Autónoma de México: por mi raza hablará el espíritu, es decir, concibe a la raza, no como simple cuestión biológica, sino como nexo entre las profundidades humanas, los sentimientos y ambiciones en relación a la proyección ciudadana, al "nosotros" con valores e identidad. Ve al mestizo mexicano como el humano del futuro.

En Vasconcelos no hay un positivismo puro, tiene influencia del vitalismo de Bergson, de Ruskin, lleva en su ser y su trabajo una admiración por la cultura clásica, por el espiritualismo, por la pasión, por ello cree en el pueblo mexicano, en el derecho de los indios, en el arte muralista de Orozco, Siqueiros y Rivera. Incluso cuando rector de la Universidad Nacional de México, mandó levantar un edificio nuevo, como local universitario y apoyó a los artistas para que plasmaran ahí su visión de la sociedad mexicana, revolucionaria y mestiza (Blanco, 1982).

Encinas aunque reclama la tierra y dice que sin tierra no hay escuela para los indígenas, tiene muy presente la cultura, el arte, la moral. En 
su tesis Causas de la criminalidad indígena hace una reevaluación de dicha población frente a las ideas hegemónicas de la época; denuncia la falta de libertad que ahoga al indio, niega una supuesta tara criminal por atavismo. Hizo estudios antropológicos en cárceles de los Andes, y dice "no tienen la vanidad del crimen...están atormentados por la crueldad de sus amos...miente por temor, no por maldad, es un instinto de conservación...la ociosidad no es su vicio, es una defensa contra el trabajo brutal" (Encinas, 1932: 79). La fuente espiritualista de Encinas es la influencia liberal y evangélica que asimiló desde niño, reconoce a las escuelas adventistas, que en Puno fundara el estadounidense Fernando Stahl (Encinas, 1932) y su esposa, como centros de respeto, de libre examen, de pragmatismo y laboriosidad. El mismo Encinas llevó a cabo, en el Centro Escolar 881, una enseñanza libre, sin exámenes, no atormentando a los niños con el feudal memorismo, sino tratando a los niños con respeto y hasta permitiendo la expresión libre del estudiante; no enseñaba religión, ni hacía rezar a los niños. Por el contrario, decía que el catolicismo, enseñado por los obispos y curas corruptos había "generado mansedumbre, una presión en la conciencia indígena y esto creado la abulia" (Encinas, 1932: 82). Escribió, sin tapujos, que el cura es el enemigo tradicional del indio. Aquí se desprende una visión laica de la educación, pero no falto de disciplina, ni de moral, la cual debía sustentarse en el trabajo -puso talleres de carpintería y artesanía- y en la solidaridad. Hay mucho liberalismo en Encinas, una gran fe en el estudio y una férrea esperanza en la unión de los peruanos para formar la nación.

Vasconcelos representa a la clase media, igual Encinas, ambos se nutren de la cultura universal, no se encierran en regionalismos, quieren traspasar las fronteras, pero incorporando al indio pues confían en él. Tanto el mexicano como el peruano fundaron bibliotecas, escuelas, propugnaban leyes a favor de la alfabetización y la educación total del indígena. Encinas organizó bibliotecas y buscaba autores europeos, norteamericanos y chilenos como representantes de la moderna pedagogía y que debía impulsarse la Escuela Normal, de donde él egresó. Asimismo, Vasconcelos dirigió la Escuela Nacional Preparatoria, medía la energía humana a través del arte (al cual calificaba de un grado superior comparado con las otras materias) y veía la muerte de miles de hombres en las guerras como el grado más bajo de interacción humana. Apuntaba a un mestizaje cultural, hacer del indio una clase media y trabajar con la educación para la democracia, buscar una mutua influencia, alcanzando así la unidad nacional. 
Encinas buscaba relacionar el trabajo manual con la geometría, crear escuelas rurales, estudiar el mito del Wiracocha, y no el bíblico, por ser más parecido al humano real. Este mito andino cuenta la existencia de un dios que no destruye ni crea al mundo; si bien es un ser que se equivoca, corrige, permitiendo a los seres humanos levantarse de los fracasos y crisis. Excelente metáfora que el maestro puneño empleaba, como estrategia didáctica, con sus pequeños estudiantes en 1910.

\section{Conclusiones}

l l sistema de control de tierras concentradas en dueños latifundistas ha sido una característica constante en muchos países de Latinoamérica. El yugo que esto generaba en la población originaria, llamada indígenas, imposibilitó que se formara la nación que muchos intelectuales, y maestros en especial, consideraban importante para contar con una sociedad fuerte, compacta, unida.

Dos hombres dedicados a la educación, la cultura y el activismo en la política dedicaron sus vidas a construir la nación a través de un proyecto educativo que incorpore al indio en el seno democrático. Contemporáneos pero distantes por el espacio geográfico, José Vasconcelos de México y José Antonio Encinas del Perú, coincidieron en labores y pensamiento, pero marcados de diferente manera por la trayectoria histórica de sus países.

En México la guerra revolucionaria que transcurrió con los campesinos, los profesionales y caudillos, condujo, no sin inconvenientes, a reformas del agro, de la educación y de la legalidad laboral que dieron un marco favorable a las propuestas de José Vasconcelos, quien buscaba que se valorara al mestizo, esa raza cósmica, mundial, nueva, sana, frente a un mundo en problemas.

En Perú, José Antonio Encinas diseñó un proyecto educativo con base en la lucha de un indigenismo temprano, a las ideas de educación moderna de la Escuela Nueva y el trabajo de la Iglesia Adventista, que se asentó en los años previos en Puno. Este programa fue duramente reprimido por los grandes propietarios de haciendas y por el clero católico, que monopolizaba el sentimiento religioso en una de las sociedades más conservadoras de Sudamérica. 


\section{REFERENCIAS BIBLIOGRÁFICAS}

Arreola Martínez, Betzabé (2009). El caudillo cultural de la nación. (Consultado 26/04/2016). Recuperado en http://www.uam.mx/difusion/casadeltiempo/25_iv_nov_2009/casa_del_tiempo eIV_num25_04_10.pdf

Blanco, José Joaquín y otros (1976). En torno a la cultura nacional. México, Instituto Nacional Indigenista.

Castillo Mireles, Rigoberto (2003). José Vasconcelos, Retazos dispersos de una vida ejemplar (consultado el 15/12/2016). Recuperado de http://Www.miggarme.com/2011/10/josevasconcelos.html

Encinas, José A. (1913). La educación, su función social. Tesis de bachiller, Lima, UNMSM

(1919). Causas de la criminalidad indígena. Tesis de derecho, UNMSM.

(1932). Un ensayo de Escuela Nueva del Perú. Lima, Munilibros.

Flores Galindo, Alberto \& Burga, Manuel (1982). Apogeo y crisis de la República Aristocrática. Lima, Rickchay.

Lozano, Saniel (1991). Proceso y horizontes del indigenismo. Trujillo, Horizonte.

Montoya, Rodrigo (1987). Revista Debate Agrario $N^{\circ} 1$, Octubre-Diciembre, Lima, Centro Peruano de Estudios Sociales.

Neira, Hugo (2005). Hacia la tercera mitad Perú siglo XVI-XX. Lima, Herética.

Ocampo López, Javier (2005). José Vasconcelos y la educación mexicana. Rhela Vol. 7 (consultado 03/08/2016). Recuperado en http://www.redalyc.org/pdf/869/86900707.pdf

Tord, Luis Enrique (1978). El indio en los ensayistas peruanos. Lima, Editoriales Unidas.

Trejo Villalobos, Raul (2010). Filosofía y vida: el itinerario filosófico de José Vasconcelos. (Consultado 23/09/2016). Recuperado en https://gredos.usal.es/jspui/bitstream/10366/83193/1/DFLFC_ TrejoVillalobos_Filosofiayvida.pdf

Vasconcelos Calderón, José (1948). La raza cósmica. (Consultado 25/12/2016). Recuperado en http://www.turemanso.com.ar/larevista/bajadas/larazacosmica.pdf 